\title{
AVALIAÇÃO ERGONÔMICA DO PROTÓTIPO DE UM MOTOCOVEADOR HIDRÁULICO, UTILIZADO EM ATIVIDADES DE SILVICULTURA FLORESTAL
}

\author{
Luciano José Minette ${ }^{1}$, Emília Pio Da Silva² ${ }^{\text {, Amaury Paulo Souza }}{ }^{3}$, Wevergton Lopes Hermsdorff ${ }^{4}$
}

\begin{abstract}
RESUMO
O objetivo deste estudo foi realizar uma análise ergonômica do protótipo do motocoveador hidráulico, levando-se em consideração os aspectos de posturas, carga de trabalho, biomecânica, ruído e vibração. As variáveis antropométricas obtidas foram utilizadas para o dimensionamento do protótipo. Os resultados evidenciaram que, dentre os movimentos realizados pelo operador, durante a atividade, destacam-se a inclinação anterior do tronco durante a fase da perfuração do solo e o transporte do equipamento de uma demarcação à outra, associados à rotação do tronco, somada à sustentação e manuseio de peso. A atividade de coveamento com o protótipo hidráulico não expõe o trabalhador a situações de sobrecarga física. Porém, durante a fase de deslocamento entre covas, $99 \%$ dos trabalhadores apresentaram riscos de lesão para a articulação do cotovelo e disco vertebral $\mathrm{L}_{5}-\mathrm{S}_{1}$ e $89 \%$ dos trabalhadores para joelhos. O ruído e a vibração emitidos pelo equipamento estão em conformidade com os valores recomendados pela Legislação Brasileira. O protótipo hidráulico apresenta, como vantagem, a possibilidade de inversão de rotação constante, tornando-o próprio para aplicação em algumas máquinas.
\end{abstract}

Palavras- chave: silvicultura florestal, protótipo hidráulico, ergonomia

\section{ABSTRACT \\ EVALUATION ERGONOMIC OF THE PROTOTYPE OF A HYDRAULIC PIT DIG USED IN ACTIVITIES OF FOREST SYLVICULTURE}

The object of this study was to conduct an ergonomic analysis of the prototype hydraulic pit dig, taking into account the aspects of posture, workload, biomechanics, vibration and noise. The anthropometric variables obtained were used for the design of the prototype. The results showed that among the movements performed by the operator during the activity, we highlight the trunk inclination during the drilling of soil and transport the equipment to draw a line to the other, associated with rotation of the trunk, plus the support and material handling. The activity of the prototype hydraulic tillage does not expose workers to situations of physical strain. However, during the phase shift between pits, $99 \%$ of workers showed risk of injury to the elbow joint and vertebral disc $\mathrm{L}_{5}-\mathrm{S}_{1}$ and $89 \%$ of workers to the knees. The noise and vibration emitted by the equipment are in accordance with the values recommended by Brazilian legislation. The prototype hydraulic presents the advantage of the possibility of reverse rotation constant, making it suitable for application on some machines.

Keywords: forest sylviculture, hydraulic Prototype, ergonomic

Recebido para publicação em 22/09/2009. Aprovado em 22/04/2010.

1- Universidade Federal de Viçosa. Professor do Departamento de Engenharia de Produção e Mecânica, e-mail: minette@ufv.br

2- Universidade Federal de Viçosa. Estudante de Doutorado do Departamento de Engenharia Florestal, e-mail: emilia.ergo@ufv.br

3- Universidade Federal de Viçosa. Professor do Departamento de Engenharia Florestal, e-mail: amaurysouza@ufv.br

4- Universidade Federal de Viçosa. Estudante de Doutorado do Departamento de Engenharia Agrícola, e-mail: wevergton@gmail.com 


\section{INTRODUÇ̃̃O}

O surgimento e a evolução de máquinas e equipamentos florestais têm-se intensificado a partir da década de 90; com isso, algumas atividades, que eram realizadas de forma rudimentar e empírica, tornaramse semimecanizadas ou mecanizadas, na atividade de implantação florestal.

A implantação de florestas de eucalipto envolve um conjunto de operações, iniciadas com o preparo do terreno e terminadas com o último trato cultural do povoamento estabelecido. As etapas geralmente são: limpeza da vegetação, abertura de carreadores e estradas, controle de erosão, controle de formigas e cupins, preparo do solo (marcação de covas, coveamento, sulcamento, adubação, correção de acidez etc.), plantio e replantio, irrigação e tratos culturais (capinas, roçadas e aplicações de herbicidas e adubos).

A introdução do motocoveador mecânico na atividade de coveamento semimecanizado possibilitou ao trabalhador abolir a forma rudimentar, utilizada anteriormente, de realizar a atividade, diminuindo o tempo de execução da tarefa. Porém, a atividade continuou apresentando elevada exigência física, merecendo, portanto, estudos para melhorar as condições de segurança, conforto e bem-estar do trabalhador.

A realização das atividades de implantação dessas florestas pode apresentar uma série de problemas ergonômicos, que, se não forem corrigidos ou prevenidos, poderão acarretar danos à saúde, bem como afetar a satisfação e o bem-estar dos trabalhadores. Esses problemas não são muito diferentes daqueles encontrados no meio rural. Os trabalhadores do meio rural estão expostos a inúmeros agentes que podem causar acidentes, como máquinas e implementos agrícolas, ferramentas manuais, transporte manual de cargas, esforços repetitivos, agrotóxicos e animais peçonhentos.

O trabalhador que atua na atividade de coveamento sobe e desce terrenos com declividade superior a $22^{\circ}$ (40\%), carregando consigo o motocoveador mecânico que pesa $15 \mathrm{~kg}$, abastecido. Além do peso da máquina, a situação de trabalho ainda é agravada pela elevada carga de esforço físico, elevado ruído, alta vibração, alta exigência de forças, posturas forçadas e inadequadas, falta de pausas e repetitividade de movimentos de modo incorreto e de forma contínua, durante toda a jornada de trabalho e por vários anos.

Sendo assim, almejando contribuir para a melhoria da segurança, da saúde, do conforto, do bem- estar e da eficiência dos trabalhadores florestais, que atuam na atividade de coveamento, foi desenvolvida uma nova máquina, levando-se em consideração o princípio da máquina hidráulica e baseada em fatores ergonômicos.

Este estudo teve como objetivo realizar avaliação ergonômica do protótipo do motocoveador hidráulico, visando a demonstrar seus efeitos para a saúde e a segurança do trabalhador.

\section{MATERIAIS E MÉTODOS}

\section{População e amostragem}

O universo do estudo foi constituído por operadores diretamente ocupados na atividade de coveamento florestal. Foi utilizado o princípio do grupo homogêneo de riscos, sendo os testes realizados com cinco operadores, atuando em áreas pertencentes à Universidade Federal de Viçosa.

\section{Descrição do protótipo do motocoveador hidráulico}

O protótipo desenvolvido com uma broca perfuradora pesa $13 \mathrm{~kg}$. Ele é um sistema motriz e perfuratriz, constituído por um motor a gasolina que aciona a bomba hidráulica, ligada à parte perfuratriz por mangueiras. Em uma base móvel fica montada a bomba hidráulica, contendo o sistema de ligação entre a base e o conjunto perfuratriz, conforme mostra a Figura 1.

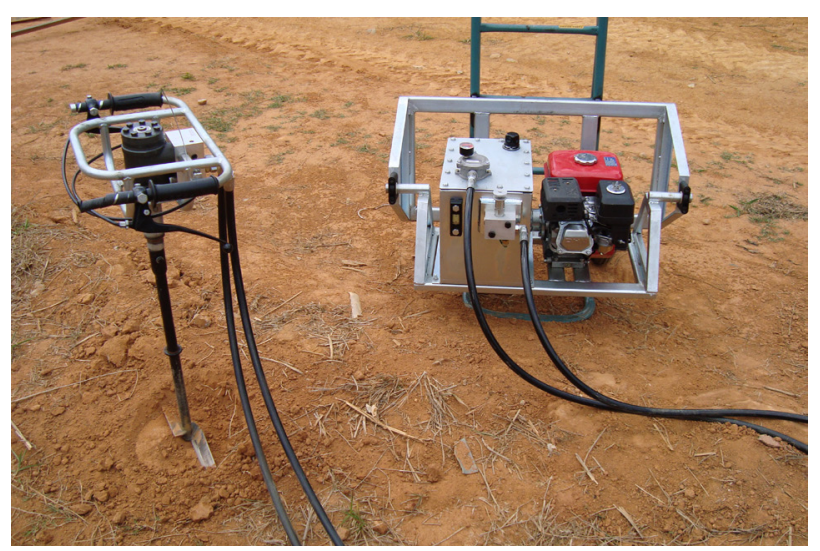

Figura 1. Protótipo hidráulico (Sistema motriz e perfuratriz).

\section{Avaliação das variáveis ergonômicas}

\section{Antropometria}

As variáveis antropométricas foram obtidas por medição direta, por meio da antropometria estática. 
Foram avaliadas as seguintes variáveis: altura do punho; altura do joelho; altura da espinha ilíaca; altura do apêndice xifoide; altura do umbigo e altura do cotovelo.

As variáveis da mão foram: largura da mão no metacarpo; largura da mão no polegar; largura da mão fechada e do círculo da mão; comprimento da mão na extremidade do dedo médio; comprimento da mão na extremidade do dedo mínimo; comprimento da palma da mão; comprimento da mão na extremidade do polegar; comprimento da mão na base do polegar; diâmetro interno da pega; diâmetro externo da mão em pega e comprimento da mão em pega.

A análise estatística dos dados foi feita mediante o uso de percentis, que é uma separatriz que divide a distribuição em 100 partes iguais, a partir do menor para o maior, em relação a algum tipo específico de dimensão corporal. Os percentis utilizados nos valores indicados para as variáveis estudadas foram 5, 50 e 95\%.

\section{Análise postural}

A análise postural e do modo operatório da tarefa foi realizada por observações in loco, a fim de se obter informações sobre a forma de execução da tarefa e do comportamento postural do operador. Foram observados o conteúdo do trabalho, o modo operatório e o comportamento cinesiológico e postural dos segmentos corporais, considerando-se os aspectos biomecânicos.

\section{Avaliação da carga de trabalho físico por meio da frequência cardíaca}

A carga de trabalho físico foi avaliada por intermédio do levantamento da frequência cardíaca durante a jornada de trabalho. Os dados foram coletados e analisados por meio do sistema Polar Eletro Oy, da Finlândia. O equipamento é formado por três partes, um receptor digital de pulso, uma correia elástica e um transmissor com eletrodos. O transmissor, fixado ao trabalhador na altura do tórax, por meio da correia elástica, emite os sinais de frequência que são captados e armazenados pelo receptor de pulso, em intervalos de tempo predeterminados.

Ao término da coleta de dados, foram eles transferidos, por meio de uma interface, para um computador, e analisados por um software desenvolvido pelo próprio fabricante para tal finalidade.
Com base nesses dados, foi possível determinar a carga de trabalho físico imposta por cada atividade e estabelecer os limites aceitáveis para uma performance contínua no trabalho, bem como ajustar a carga de trabalho físico à capacidade dos trabalhadores, para melhoria dos seus níveis de saúde, de bem-estar e de satisfação. Esses dados permitiram calcular a carga cardiovascular no trabalho, conforme metodologia proposta por Apud (1999).

\section{Avaliação biomecânica da atividade}

A avaliação biomecânica foi realizada por meio da análise bidimensional, utilizando-se a técnica de gravação em vídeo. Os movimentos foram "congelados", para medição dos ângulos dos diversos segmentos corpóreos. As forças envolvidas foram medidas, para aplicação do programa computacional de modelo biomecânico bidimensional de predição de posturas e forças estáticas, desenvolvido pela Universidade de Michigan, Estados Unidos.

A análise por meio do programa computacional forneceu a carga-limite recomendada (CLR), que corresponde ao peso que mais de $99 \%$ dos homens e mais de $75 \%$ das mulheres conseguem levantar sem causar danos às articulações do corpo. Além disso, forneceu a carga-limite superior (CLS), que representa alto risco de lesão para determinada articulação, numa atividade em que menos de $25 \%$ das pessoas são capazes de realizá-la com segurança.

Este software permitiu, também, estabelecer a força de compressão no disco $\mathrm{L}_{5}-\mathrm{S}_{1}$ da coluna vertebral. Uma força de compressão de até 3.426,4 N sobre o disco $\mathrm{L}_{5}-\mathrm{S}_{1}$ poderá ser tolerada pela maioria dos trabalhadores jovens e em boas condições de saúde, sendo esse o limite máximo, o qual corresponde à carga-limite de compressão no disco (CLCD). Com o uso do mencionado programa, é possível também determinar a carga-limite de compressão superior no disco (CLCS), que é da ordem de 6.464,1 N. Valores de CLCS iguais ou superiores podem causar sérios danos ao sistema osteomuscular, inclusive ruptura do disco intervertebral. Os valores entre 4.426,4 $\mathrm{N}$ e $6.464,1 \mathrm{~N}$ apresentam riscos para a saúde do trabalhador.

\section{Ruído}

Os níveis de ruído no ambiente de trabalho foram obtidos utilizando-se um dosímetro digital portátil. 
Para realizar a coleta dos dados, o doseBadge foi fixado na gola da camisa, o mais próximo possível da zona auditiva.

Os dados foram analisados e confrontados com os limites determinados pela Legislação Brasileira de Atividades e Operações Insalubres (NR 15 anexo $\mathrm{n}^{\mathrm{o}} 1$, da Portaria $\mathrm{n}^{\circ} 4.214 / 78$, do Ministério do Trabalho e Emprego).

\section{Vibração}

A metodologia de avaliação foi baseada nas normas da ISO (Organização Internacional para a Normalização, em suas normas ISO 5349), conforme determina a NR-15, anexo 8, da Portaria 3214/78 - MTE. Foram analisados o ciclo de trabalho e a determinação do tempo de exposição em cada tarefa/operação realizada ao longo da jornada de trabalho, bem como a aceleração em m $\mathrm{s}^{-2}$ em cada situação diferente de exposição.

Para medição da vibração, foi utilizado um medidor de vibração MAESTRO $01 \mathrm{DB}$, acoplado a um acelerômetro triaxial montado no ponto de onde a energia é transmitida às mãos. Esse instrumento fornece os valores da magnitude de aceleração em $\mathrm{m} \mathrm{s}^{-2}$, ponderada, nas frequências de $5 \mathrm{a} 1500 \mathrm{~Hz}$.

Os dados foram comparados com os limites da ACGIH, que são aceitos cientificamente pela NR-9 da Portaria 4214/78.

\section{RESULTADOS E DISCUSSÃO}

\section{Antropometria}

As medidas antropométricas devem ser realizadas diretamente, tomando-se uma amostra significativa de sujeitos que serão usuários ou consumidores do objeto projetado (IIDA, 1990). Sendo assim, para a construção do protótipo hidráulico foi necessária a obtenção das medidas antropométricas dos operadores.

Os resultados do perfil antropométrico das variáveis estáticas dos operadores encontram-se nos Quadros 1 e 2, relativos ao indivíduo em pé e ao tamanho da mão, respectivamente, em que encontram-se analisados os percentis 5,50 e $95 \%$, a média, o desvio-padrão e o coeficiente de variação.

As medidas antropométricas são estabelecidas em várias faixas, entre o mínimo e o máximo. $\mathrm{O}$ uso desses critérios depende do tipo de projeto, das

Quadro 1. Percentis, Média, Desvio-Padrão e Coeficiente de Variação do Levantamento Antropométrico dos Operadores (Indivíduo em Pé)

\begin{tabular}{|l|c|c|c|c|c|c|}
\hline \multirow{2}{*}{\multicolumn{1}{|c|}{ Variável }} & \multicolumn{3}{|c|}{ Percentis Encontrados } & \multirow{2}{*}{$\begin{array}{c}\text { Média } \\
(\mathrm{cm})\end{array}$} & $\begin{array}{c}\text { Desvio } \\
\text { Padrão }(\mathrm{cm})\end{array}$ & $\begin{array}{c}\text { Coeficiente de } \\
\text { Variação }\end{array}$ \\
\cline { 2 - 4 } & $5 \%$ & $50 \%$ & $95 \%$ & 81,2 & 4,1 & 1,7 \\
\hline Altura do punho & 75,0 & 81,0 & 88,0 & 81,2 & 2,1 & 4,9 \\
\hline Altura do joelho & 45,0 & 48,0 & 52,6 & 48,2 & 2,2 \\
\hline Altura da espinha ilíaca & 89,5 & 95,8 & 105,0 & 95,9 & 4,7 & 2,2 \\
\hline Altura apêndice xifoide & 111,1 & 119,5 & 128,8 & 119,0 & 5,3 & 2,8 \\
\hline Altura do umbigo & 95,4 & 100,5 & 111,4 & 102,2 & 5,6 & 3,1 \\
\hline Altura do cotovelo & 97,6 & 105,0 & 113,9 & 105,5 & 4,7 & 2,2 \\
\hline
\end{tabular}

Quadro 2. Percentis, Média, Desvio-Padrão e Coeficiente de Variação do Levantamento Antropométrico dos Operadores (Dimensões da Mão)

\begin{tabular}{|c|c|c|c|c|c|c|}
\hline \multirow{2}{*}{ Variável Antropométrica } & \multicolumn{3}{|c|}{$\begin{array}{l}\text { Percentis Encontrados } \\
(\mathrm{cm})\end{array}$} & \multirow{2}{*}{$\begin{array}{l}\text { Média } \\
(\mathrm{cm})\end{array}$} & \multirow{2}{*}{$\begin{array}{l}\text { Desvio- } \\
\text { Padrão } \\
(\mathrm{cm})\end{array}$} & \multirow{2}{*}{$\begin{array}{c}\text { Coeficiente } \\
\text { de } \\
\text { Variação } \\
(\mathrm{cm})\end{array}$} \\
\hline & $5 \%$ & $50 \%$ & $95 \%$ & & & \\
\hline Largura da mão no metacarpo & 8,0 & 9,0 & 9,6 & 8,9 & 0,5 & 0,3 \\
\hline Largura da mão no polegar & 9,5 & 10,5 & 11,5 & 10,5 & 0,7 & 0,5 \\
\hline Largura da mão fechada & 7,0 & 8,0 & 8,8 & 7,8 & 0,5 & 0,3 \\
\hline Comprimento da mão na extremidade do dedo médio & 16,9 & 19,5 & 21,6 & 19,1 & 1,7 & 2,8 \\
\hline Comprimento da mão na extremidade do dedo mínimo & 14,2 & 15,5 & 17,0 & 15,6 & 0,8 & 0,7 \\
\hline Comprimento da palma da mão & 9,5 & 10,5 & 11,8 & 10,5 & 0,7 & 0,4 \\
\hline Comprimento da mão na extremidade do polegar & 11,4 & 13,5 & 15,3 & 13,4 & 1,1 & 1,4 \\
\hline Comprimento da mão na base do polegar & 5,5 & 6,8 & 7,7 & 6,7 & 0,7 & 0,4 \\
\hline Diâmetro interno da pega & 5,3 & 7,1 & 11,4 & 6,9 & 0,5 & 0,7 \\
\hline Diâmetro externo da mão em pega & 9,1 & 10,2 & 11,4 & 9,8 & 0,7 & 0,8 \\
\hline Comprimento da mão em pega & 9,9 & 12 & 14 & 12,8 & 1,1 & 1,2 \\
\hline
\end{tabular}


aplicações e das finalidades das medidas.

Foi observado na empresa que existem, com frequência, trocas de função entre os funcionários, portanto, estas variáveis podem ser utilizadas no dimensionamento de postos de trabalhos que satisfaçam esses operadores.

Dessa forma, procurou-se relacionar algumas variáveis do levantamento antropométrico estático, que podem contribuir para um dimensionamento adequado tanto da máquina de trabalho, quanto da atividade envolvida.

\section{Análise postural}

Dentre os movimentos realizados pelo operador com o motocoveador hidráulico, destacam-se a inclinação anterior do tronco durante a fase da perfuração do solo e o transporte do equipamento de uma demarcação à outra, associados à rotação do tronco, somada à sustentação e manuseio de peso. De acordo com Iida (1990), quando os trabalhadores adotam posturas inadequadas, como as citadas acima, e as mantêm por um longo período de tempo, podem surgir dores localizadas nos músculos solicitados para a conservação das posturas. Além disso, o manuseio de peso tem sido uma das mais frequentes causas de trauma dos trabalhadores.

Para Silva (2007), o levantamento de carga pode causar sérios danos às articulações dos membros inferiores dos trabalhadores, provocando desgaste articular, tendinites, lesão do menisco e ruptura dos ligamentos.

No Quadro 3 ilustram-se as posturas adotadas pelos operadores durante a fase de coveamento e transporte do protótipo hidráulico.

\section{Avaliação da carga de trabalho por meio da frequência cardíaca}

Para a realização da atividade de coveamento, a carga cardiovascular exigida pelo trabalhador foi de $38 \%$, valor que não está acima do recomendado por Apud (1989); mesmo assim, o ciclo de trabalho avaliado permite classificar a atividade como moderadamente pesada, visto que a frequência cardíaca média durante toda a jornada de trabalho foi de $112 \mathrm{bpm}$.

Para Couto (1995), durante uma jornada de trabalho de $8 \mathrm{~h}$, a frequência cardíaca não deve exceder a 110 bpm. O mesmo autor (1983) afirma que, quando o trabalhador é exigido acima do limite, a consequência é fadiga física, que pode se manifestar das seguintes maneiras: tendência a cãibras, dores musculares, lombalgias e tendinites; absenteísmo; tremores e erros que podem levar a acidentes; envelhecimento precoce; uso excessivo do álcool como fonte de energia e redução do ritmo e qualidade do trabalho.

Para que os trabalhadores não comprometam sua saúde, ficando expostos a doenças, afastamentos provisórios e permanentes e incapacidade; é importante que não desenvolvam suas tarefas sob condições de sobrecarga física.

Quadro 3. Posturas adotadas pelos operadores durante a atividade de coveamento com o protótipo hidráulico

\begin{tabular}{|c|c|c|c|}
\hline Atividade & Ação do operador & Segmentos corporais & Posturas adotadas \\
\hline \multirow{4}{*}{ Covear } & $\begin{array}{l}\text { Posicionar o protótipo } \\
\text { sobre a demarcação }\end{array}$ & $\begin{array}{l}\text { Membro superior Direito } \\
\text { e Esquerdo }\end{array}$ & $\begin{array}{l}\text { - Flexão do cotovelo } \\
\text { - Sustentação do antebraço associada à } \\
\text { abdução de ombro + peso da carga }\end{array}$ \\
\hline & Perfurar a cova & $\begin{array}{l}\text { - Mão Direita e esquerda } \\
\text { - Coluna vertebral }\end{array}$ & $\begin{array}{l}\text { - Extensão forçada de cotovelos } \\
\text { - Preensão da mão } \\
\text { - Inclinação anterior do troco }\end{array}$ \\
\hline & \multirow{2}{*}{$\begin{array}{l}\text { Acionar manete de } \\
\text { fluxo de óleo }\end{array}$} & - Mão direita & \multirow[b]{2}{*}{ - Preensão dedos } \\
\hline & & - Mão esquerda & \\
\hline \multirow[b]{2}{*}{$\begin{array}{l}\text { Transportar } \\
\text { o protótipo }\end{array}$} & $\begin{array}{l}\text { Retirar a broca da cova } \\
\text { e elevar o protótipo }\end{array}$ & $\begin{array}{l}\text { - Membro superior direito } \\
\text { e esquerdo }\end{array}$ & $\begin{array}{l}\text { - Flexão de cotovelo } \\
\text { - Elevação do ombro }\end{array}$ \\
\hline & $\begin{array}{l}\text { Transportar o protótipo } \\
\text { até a próxima demarcação }\end{array}$ & $\begin{array}{l}\text { - Membro superior direito } \\
\text { e esquerdo } \\
\text { - Membros inferiores } \\
\text { - Coluna dorsal }\end{array}$ & $\begin{array}{l}\text { - Flexão de cotovelo associada à abdução } \\
\text { de ombro + sustentação de peso da carga } \\
\text { - Deambulação } \\
\text { - Extensão da coluna dorsal? } \\
\text { - Rotação do tronco (na descida) }\end{array}$ \\
\hline
\end{tabular}




\section{Avaliação biomecânica da atividade}

A sobrecarga postural e o trabalho estático podem gerar fadiga muscular, transtornos nos músculos esqueléticos, compressão de estruturas nervosas e até mesmo o agravamento de lesões prévias nos tecidos moles (músculos, ligamentos) dos membros inferiores (COUTO, 1995). As exigências físicas e os riscos posturais da atividade de coveamento estão descritas abaixo.

$\mathrm{Na}$ fase de deslocamento entre covas, $99 \%$ dos trabalhadores apresentam riscos de lesão para a articulação do cotovelo e disco vertebral $\mathrm{L}_{5}-\mathrm{S}_{1}$ e $89 \%$ dos trabalhadores para joelhos.

No Quadro 4, apresentam-se o resumo da análise biomecânica para a atividade de coveamento. Para cada uma das fases dessas atividades, é mostrado se as articulações apresentam ou não algum problema causado pela carga de trabalho. A sigla SRL representa "Sem Risco de Lesão nas Articulações", ou seja, mais de $99 \%$ dos trabalhadores conseguem suportar a carga imposta pela atividade, sem risco para as articulações envolvidas, e a sigla CLR representa "Carga Limite Recomendada Ultrapassada", ou seja, menos de 99\% dos trabalhadores conseguem suportar a carga imposta pela atividade sem risco para as articulações envolvidas.

Os resultados da análise evidenciaram que a atividade oferece risco de compressão do disco vertebral $\mathrm{L}_{5}-\mathrm{S}_{1}$ na fase de perfurar covas, por uma força de $4709,0 \mathrm{~N}$.

Os distúrbios dos discos vertebrais são decorrentes de forças de compressão elevadas; esses distúrbios podem ocasionar dor muito forte e extremamente incapacitante, acabando por gerar afastamentos prolongados e, até mesmo, permanentes, já que os indivíduos têm incapacidade para atividades pesadas (COUTO, 2002).

\section{Ruído}

O resultado das análises dos níveis de ruído da avaliação do protótipo hidráulico variou de 78,1 a 83 $\mathrm{dB}(\mathrm{A})$, durante a realização da atividade de coveamento. Estes valores encontram-se em conformidade com os valores estabelecidos pela Legislação Brasileira, para uma jornada de 8 horas de trabalho.

O protótipo do motocoveador hidráulico foi planejado para evitar níveis de ruído acima do permitido pela Legislação Brasileira. Segundo Kroemer \& Grandjean (2005) não gerar ruído é a melhor forma de combater o ruído.

\section{Vibração}

De a acordo com a Directiva Europeia, os valores de exposição que desencadeiam a ação ao sistema mão-braço para um período de referência de 8 horas $\mathrm{A}(8)$ é fixado em $2,5 \mathrm{~m} \mathrm{~s}^{-2}$, quando ultrapassa este nível os efeitos sobre a saúde e a segurança dos trabalhadores poderão estar sujeitos a riscos especialmente sensíveis.

O nível de vibração Global $\mathrm{A}(8)$ do protótipo hidráulico, apresentado no Quadro 5, foi inferior aos valores recomendados pela Directiva Europeia. Os valores 5,01 e 3,60 do protótipo hidráulico estão próximos e inferiores ao nível limite $\mathrm{A}(8)$.

Quadro 4. Resumo da análise biomecânica para as atividades de coveamento

\begin{tabular}{|c|c|c|c|c|c|c|c|c|}
\hline \multirow[t]{2}{*}{ Atividade } & \multirow{2}{*}{$\begin{array}{ll}\text { Fase do } \\
\text { Ciclo }\end{array}$} & \multirow{2}{*}{$\begin{array}{l}\text { Pos t u r a } \\
\text { e s t á t i c a } \\
\text { selecionada } \\
\text { para análise }\end{array}$} & \multicolumn{6}{|c|}{$\begin{array}{l}\text { Articulações e suas respectivas condições de suportar a carga, sendo } \\
\text { Sem Risco de Lesão (SRL) e com risco de lesão, ou seja, Carga Limite } \\
\text { Recomendada Ultrapassada (CLR) }\end{array}$} \\
\hline & & & $\begin{array}{l}\text { Coto- } \\
\text { velos }\end{array}$ & Ombros & $\begin{array}{l}\text { Disco } \\
\text { L5/S1 }\end{array}$ & $\begin{array}{l}\text { Coxofe- } \\
\text { morais }\end{array}$ & Joelhos & Tornozelos \\
\hline \multirow{2}{*}{ Covear } & $\begin{array}{l}\text { Perfurar } \\
\text { cova }\end{array}$ & & SRL & SRL & SRL & SRL & SRL & SRL \\
\hline & $\begin{array}{l}\text { Desloca- } \\
\text { m e n t o } \\
\text { entre } \\
\text { covas }\end{array}$ & & CLR & CLR & CLR & CLR & CLR & CLR \\
\hline
\end{tabular}


Quadro 5. Níveis de vibração global gerado pelo protótipo hidráulico

\begin{tabular}{|c|c|c|c|c|c|c|c|c|}
\hline \multirow[b]{2}{*}{$\begin{array}{l}\text { Motocoveador } \\
\text { Hidráulico }\end{array}$} & \multirow[b]{2}{*}{ Mão } & \multicolumn{6}{|c|}{ Aceleração $\left(\mathrm{m} \mathrm{s}^{-2}\right)$} & \multirow[b]{2}{*}{$\begin{array}{c}\text { Exposição } \\
\text { (Trabalho de 8h) }\end{array}$} \\
\hline & & $\mathrm{X}$ & Y & Z & $\begin{array}{l}\text { Global } \\
\text { Aeq }\end{array}$ & $\begin{array}{l}\text { Axe } \\
\text { Max. }\end{array}$ & $\begin{array}{l}\text { Global } \\
\mathrm{A}(8)\end{array}$ & \\
\hline $\begin{array}{l}\text { Níveis observados } \\
\qquad\left(\mathrm{m} \mathrm{s}^{-2}\right)\end{array}$ & \multirow{3}{*}{ direita } & 2,04 & 3,81 & 3,51 & 5,57 & 3,81 & 5,57 & $5,57 \mathrm{~m} \mathrm{~s}^{-2}$ \\
\hline Nível de alerta $\left(\mathrm{m} \mathrm{s}^{-2}\right)$ & & - & - & - & - & - & 2,50 & $1 \mathrm{~h} 37 \mathrm{~min}$ \\
\hline Nível limite $\left(\mathrm{m} \mathrm{s}^{-2}\right)$ & & - & - & - & - & - & 5,00 & $6 \mathrm{~h} 27 \mathrm{~min}$ \\
\hline $\begin{array}{c}\text { Níveis observados } \\
\left(\mathrm{m} \mathrm{s}^{-2}\right)\end{array}$ & \multirow{3}{*}{ direita } & 1,14 & 2,17 & 2,64 & 3,60 & 2,64 & 3,60 & $3,60 \mathrm{~m} \mathrm{~s}^{-2}$ \\
\hline Nível de alerta $\left(\mathrm{m} \mathrm{s}^{-2}\right)$ & & - & - & - & - & - & 2,50 & $3 \mathrm{~h} 52 \mathrm{~min}$ \\
\hline Nível limite $\left(\mathrm{m} \mathrm{s}^{-2}\right)$ & & - & - & - & - & - & 5,00 & $15 \mathrm{~h} 26 \mathrm{~min}$ \\
\hline $\begin{array}{c}\text { Motocoveador } \\
\text { Hidráulico } \\
\end{array}$ & Mão & $\mathrm{X}$ & Y & Z & $\begin{array}{c}\text { Global } \\
\text { Aeq }\end{array}$ & $\begin{array}{l}\text { Axe } \\
\text { Max. }\end{array}$ & $\begin{array}{c}\text { Global } \\
\mathrm{A}(8)\end{array}$ & $\begin{array}{c}\text { Exposição } \\
\text { (Trabalho de 8h) }\end{array}$ \\
\hline $\begin{array}{l}\text { Níveis observados } \\
\qquad\left(\mathrm{m} \mathrm{s}^{-2}\right)\end{array}$ & \multirow{3}{*}{ esquerda } & 2,07 & 4,01 & 2,19 & 5,01 & 4,01 & 5,01 & $5,01 \mathrm{~m} \mathrm{~s}^{-2}$ \\
\hline Nível de alerta $\left(\mathrm{m} \mathrm{s}^{-2}\right)$ & & - & - & - & - & - & 2,50 & $1 \mathrm{~h} 59 \mathrm{~min}$ \\
\hline Nível limite $\left(\mathrm{m} \mathrm{s}^{-2}\right)$ & & - & - & - & - & - & 5,00 & $7 \mathrm{~h} 57 \mathrm{~min}$ \\
\hline
\end{tabular}

\section{CONCLUSÕES}

- A atividade de coveamento, quando realizada com o protótipo hidráulico, não expõe o trabalhador a situações de sobrecarga física;

- A fase de deslocamento entre covas expõe os trabalhadores florestais a risco de lesões articulares, sendo que $99 \%$ dos trabalhadores podem apresentar lesão no cotovelo e disco vertebral $\mathrm{L}_{5}-\mathrm{S}_{1}$ e $89 \%$ nos joelhos;

- O ruído emitido pelo protótipo hidráulico está em conformidade com os valores recomendados pela Legislação Brasileira;

- Os valores 5,01 e 3,60 do protótipo hidráulico estão próximos e inferiores ao nível limite $\mathrm{A}(8)$;

- A vantagem do protótipo hidráulico desenvolvido é a possibilidade de inversão de rotação constante, tornando-o próprio para aplicação em algumas máquinas.

\section{REFERÊNCIAS BIBLIOGRÁFICAS}

APUD, E.; GUTIÉRREZ, M.; LAGOS, S.; MAUREIRA, F.; MEYER, F.; ESPINOSA, J. Manual de Ergonomia Forestal. Chile: Laboratório de Ergonomia de la Universidad de
Concepción, 1999. 313p.

APUD, Elias. Guidelines on ergonomics study in forestry. Genebra: ILO, 1989. 241p.

COUTO, H. A. Ergonomia Aplicada ao Trabalho em 18 lições. Belo Horizonte: Ergo Editora, 2002. 202p.

COUTO, H. A. Ergonomia aplicada ao trabalho. O manual técnico da máquina humana. Belo Horizonte: Ergo Editora, 1995. 353p.

COUTO, H.A. Fadiga física no trabalho. Belo Horizonte, Ergo Editora, 1983, 42p. (Cadernos Ergo, 5).

IIDA, I. Ergonomia: projeto e produção. São Paulo: Editora Edgard Blucher, 1990. 465p.

KROEMER, K. H. E. e GRANDJEAN, E. Manual de ergonomia: adaptando o trabalho ao homem. 5 ed. Porto Alegre: Editora Bookman, 2005. 327p.

NORMA ISO 5349-1 - Measurement and evaluation of human exposure to handtransmitted vibration - General requirements, 2001. p.24. 
NORMA ISO 5349-2 - Measurement and evaluation of human exposure to handtransmitted vibration - Practical guidance for measurement at the workplace, 2001. p.39.

NORMA REGUlamentadora 9. Programa de prevenção de riscos ambientais, CLT Capítulo V, Título II. Diário Oficial da União, 8 Jun 1978.

NORMA

REGULAMENTADORA
Atividades e operações insalubres, CLT Capítulo V, Título II. Diário Oficial da União, 8 Jun de 1978.

SILVA, E. P. Avaliação de fatores ergonômicos em operações de extração florestal em terrenos montanhosos na região de Guanhães - MG. 2007. 125f. Dissertação (Mestrado em Ciência Florestal) Universidade Federal de Viçosa, Viçosa, MG, 15. 2007. 